\title{
ПРОБЛЕМЫ ГОСТИНИЧНОГО БИЗНЕСА В УСЛОВИЯХ ПАНДЕМИИ (КОРОНАВИРУСА)
}

\section{PROBLEMS OF HOTEL BUSINESS IN THE CONDITIONS OF PANDEMIC (CORONAVIRUS)}

\section{E. Shumakova}

Summary. The article is devoted to the consideration of the key problems of the hotel business in a pandemic (coronavirus). Particular attention is paid to the current situation in the hospitality industry. In addition, promising areas for the development of the hotel business in the future and methods for overcoming the crisis are highlighted. So, the emphasis is on the need for state support of hoteliers, the increased use of digital technologies by hotels and special offers for travel planning, the introduction of measures to reduce the risk of cancellation.

Keywords: hotel, pandemic, profit, reservation, travel.

\author{
Шумакова Елена Викторовна \\ К.э.н., дочент, Дальневосточный Федеральный \\ университет, г. Владивосток \\ shumakova.ev@dvfu.ru
}

Аннотация. Статья посвящена рассмотрению ключевых проблем гостиничного бизнеса в условиях пандемии (коронавируса). Особое внимание уделено текущей ситуации в индустрии гостеприимства. Кроме того, выделены перспективные направления развития отельного бизнеса в будущем и методы преодоления кризиса. Так, акцент сделан на необходимости государственной поддержки отельеров, активизации использования отелями цифровых технологий и специальных предложений для планирования поездок, внедрения мер по снижению риска отмены бронирования.

Ключевые слова: отель, пандемия, прибыль, бронь, путешествия.

ходах. Кроме того, гостиничная индустрия, как и любой другой бизнес, в нынешних условиях претерпевает ряд существенных проблем, связанных, в том числе, с экономическим кризисом, нестабильной политической обстановкой в мире, и, в последнее время, с охватившей весь мир пандемией коронавируса.

Как свидетельствуют данные ЮНВТО все классы отелей понесли убытки в результате пандемии, как в развитых, так и в развивающихся странах.

Так, например, в Европе, наибольший ущерб был причинен высококлассным гостиничным комплексам (см. рис. 1).

Согласно информации «РосинвестОтель» в России сильнее всего пострадали гостиничные рынки Москвы, Владивостока, Санкт-Петербурга. По подсчетам журнала Forbes убытки гостиниц в Москве и Санкт-Петербурге изза коронавируса ежедневно составляют 258 млн. руб. [4].

Очевидно, пандемия коронавируса еще на протяжении продолжительного периода времени будет оказывать негативное воздействие на гостиничный бизнес, трансформируя и полностью меняя существующую до сих пор тенденцию развития.

В данном контексте особую значимость приобретают вопросы, связанные с адекватной оценкой последствий 


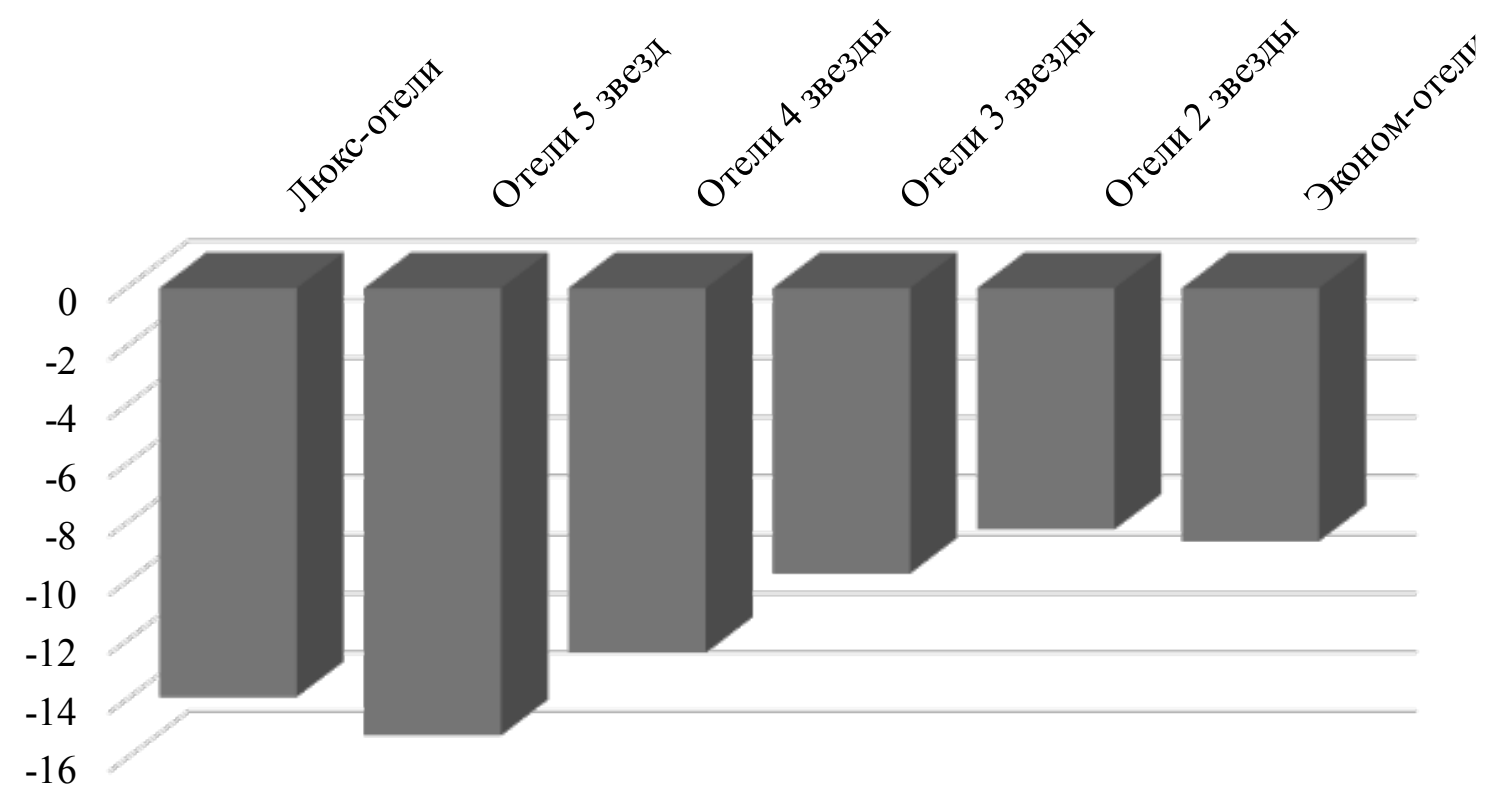

Рис. 1. Падение доходов европейских отелей на номер по состоянию на 07.03.2020, (\%) [3]

пандемии и разработкой эффективных мер, способных помочь отрасли преодолеть кризис, что и предопределяет выбор темы данной статьи.

Исследованию вопросов антикризисного управления предприятиями гостиничного бизнеса посвятили свои работы отечественные и зарубежные ученые, в частности А.М. Виноградская, Ю.А. Палеха, В.И. Чубук, Г.Б. Юн, Е. М. Коротков, Дж. Кестер и др.

Меры государственной поддержки сферы гостеприимства в целом рассматривали Котлер Ф., Кох А., Любицева А., Мюллер Б., Райан К., Федякина А., Фрайер В., Штайнеке А и др.

Однако, несмотря на значительное количество научных и практических наработок, посвященных управлению и развитию гостиничного бизнеса в период нестабильности и неопределенности, очевидно, что пандемия коронавируса 2019-2020 гг. не имела аналогов во всем мире до сегодняшнего дня, поэтому вопросы связанные со способами ее преодоления, методами нивелирования негативных последствий и выработкой перспективных векторов развития в ближайшем будущем остаются открытыми.

Отдельный акцент следует сделать на том, что наибольшему риску подвержены малые средства размещения и несетевые гостиничные объекты, работающие на арендованных площадях.

Поэтому, с учетом вышеизложенного, цель статьи заключается в рассмотрении проблем функционирова- ния гостиничного бизнеса в условиях пандемии (коронавируса) и обосновании практических рекомендаций по преодолению кризисных явлений.

Главные проблемы гостиничного бизнеса в период пандемии коронавируса связаны со снижением потока гостей, стремительным падением доходов, а также с появлением кассового разрыва. Отсутствие доходных поступлений вызвало необходимость многих отельеров отпустить практически всех сотрудников в отпуск за свой счет до окончания карантина, остановить рекламные кампании и другие расходы.

На сегодняшний день ситуация с пандемией очень нестабильна, поэтому составлять прогнозы развития отрасли на ближайшее будущее не представляется возможным. При этом очевидным является тот факт, что 2020 год будет очень сложным для гостиничной индустрии. На повестке дня стоят задачи сохранить в дееспособном состоянии инфраструктуру, попытаться избежать потерь и уменьшить сокращение персонала до минимума.

Итак, рассмотрим более подробно какие меры позволят преодолеть кризис в сфере гостиничного бизнеса.

Мировое научное сообщество сегодня сходится во мнении, что после пандемии без вмешательства правительства не будет никакой сферы услуг вообще, в том числе и услуг гостеприимства. Поэтому одним из вариантов вывода отрасли из кризиса является государственная помощь и улучшение для бизнеса условий 


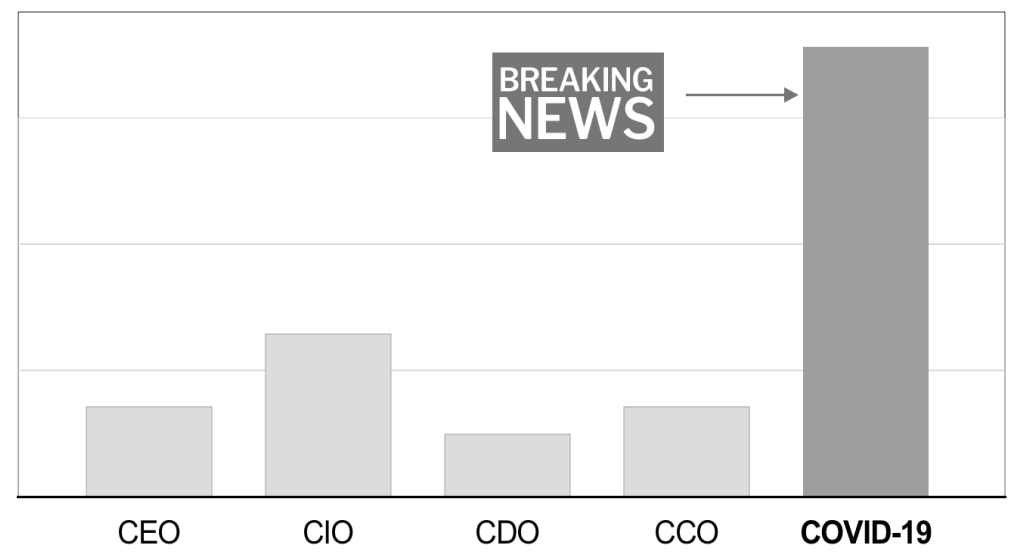

Рис. 2. Факторы, способствующие цифровым трансформациям отелей в 2020 году [5]

при оплате ипотеки. Например, правительство США разработало программу, в соответствии с которой любому гостиничному бизнесу с численностью до 500 человек будет предоставляться безвозвратные кредиты в сумме до 2,5 размеров ежемесячного фонда оплаты труда сотрудников.

Вторым эффективным инструментом, который позволит гостиничному бизнесу преодолеть турбулентность, является активное использование цифровых технологий.

В прошлом отельеры, возможно, и не задумывались об управлении своими отелями на расстоянии, но во время пандемии коронавируса стало очевидно, что технологические решения, благодаря которым сотрудники могут получить удаленный доступ, имеют решающее значение для поддержания работоспособности в условиях социального дистанцирования.

Уже сегодня опросы собственников отельного бизнеса свидетельствуют о том, что пандемия способствовала активному использованию передовых информационно-коммуникационных технологий (см. рис. 2).

Приведем пример направлений использования цифровых технологий в отелях. Так, облачные системы управления имуществом позволяют владельцам отелей управлять своими бизнес-процессами, находясь на удалении, в отличие от старых локальных систем, доступ к которым сотрудники могут получить только на компьютерах отелей. Причем эти технологии позволяют управлять процессами, начиная от бронирования и заканчивая установлением ценовых предложений.

«Облачные» системы обмена сообщениями с гостями позволят владельцам гостиниц общаться со своими гостями по поводу изменений в бронировании, правил отмены бронирования и возврата денег.

Непосредственно для оживления бизнеса значительную роль играют приобретающие на сегодня популярность программы «Купи сейчас, отдыхай позже», «Гостиничные кредиты» и «Путешествие в будущем».

Суть этих программ сводится к тому, что путешественники могут приобретать облигации и кредиты для поддержки отелей во время вспышки коронавируса и либо использовать их в будущем для отдыха, либо выкупать у отелей с дисконтом.

Также представляется целесообразным отелям в условиях ограничения международных путешествий сосредоточиться на местных туристах. Рекламные кампании с географической ориентацией позволят персонализировать контент отеля в зависимости от местоположения посетителя сайта. Отображение более релевантного контента и акцентирование внимания на других источниках дохода поможет покрыть некоторую часть падения доходов.

Помимо этого, выходом из ситуации может быть предложение о бесплатной отмене бронирования. Использование опции бесплатной отмены брони на будущие даты может снизить предполагаемый риск финансовых потерь для отеля и дать больше шансов в привлечении клиентов.

Таким образом, перспективы преодоления гостиничным бизнесом последствий пандемии коронавируса заключается в расширении использования цифровых технологии, реализации адекватной мер поддержки государством, использовании специальных программ планирования поездок в будущем, снижении риска отмены бронирования. 


\section{ЛИТЕРАТУРА}

1. Шумакова Е. В. Переход к обязательной классификация гостиниц и иных средств размещения как новое направление повышения их конкурентоспособности // Экономика: вчера, сегодня, завтра. 2019. Том 9. № 8А. С. 321-326

2. Fissi, Silvia Building a business model for a new form of hospitality: the albergo diffuso // International journal of contemporary hospitality management. 2020. Volume 32: Number 1; pp 307-323.

3. EPRS. European Parliamentary Research Service URL: https://www.europarl.europa.eu/

4. Счет пошел на триллионы: сколько российский бизнес потеряет из-за пандемии URL: https://www.forbes.ru/biznes/396055-schet-poshel-na-trilliony-skolkorossiyskiy-biznes-poteryaet-iz-za-pandemii

5. Coronavirus: Survival of the Fittest for Hotels URL: https://hoteltechreport.com/news/coronavirus

(с) Шумакова Елена Викторовна ( shumakova.ev@dvfu.ru ).

Журнал «Современная наука: актуальные проблемы теории и практики»

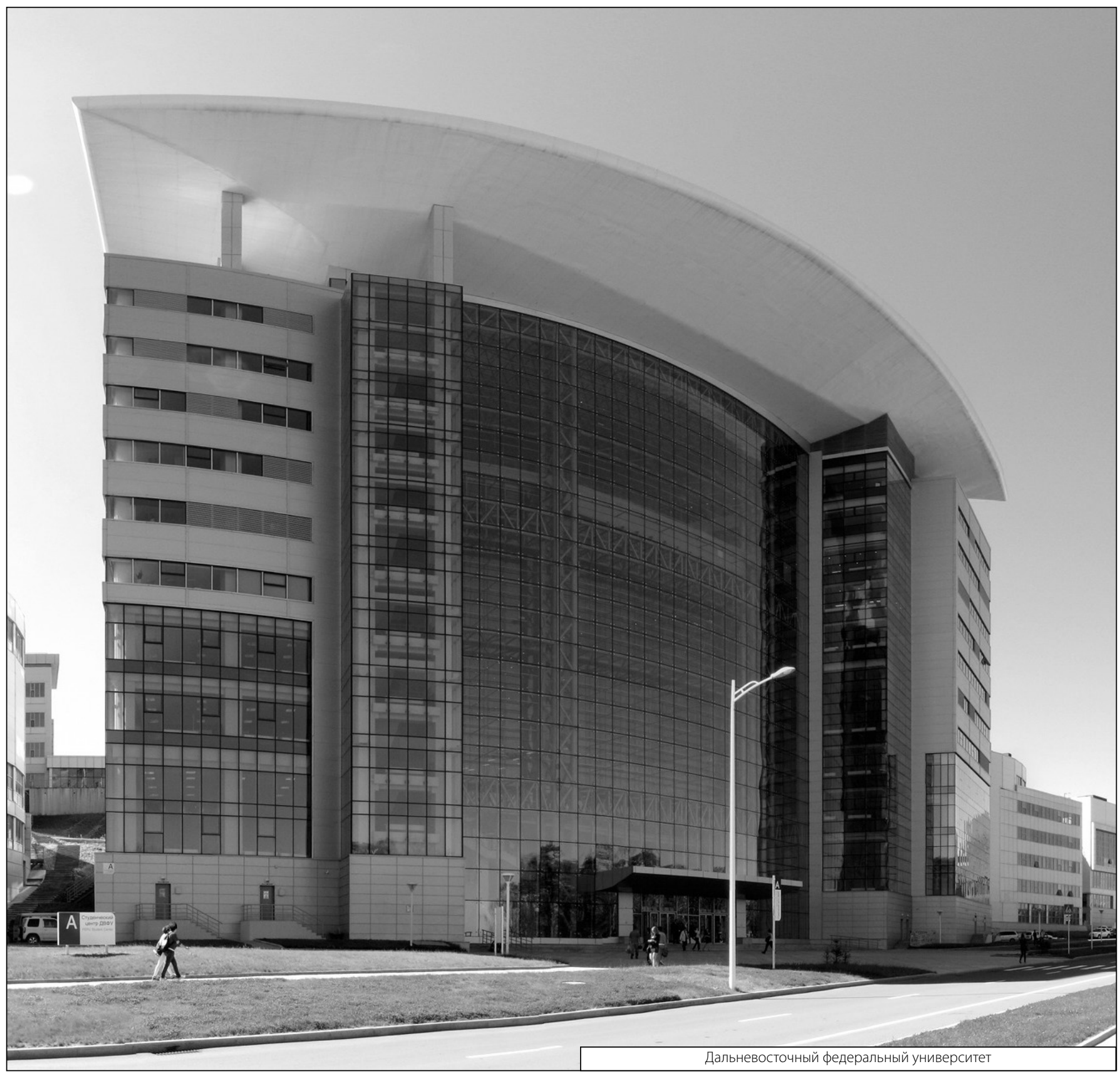

